\title{
Improving the Quality of Bowel Preparation: One Step Closer to the Holy Grail?
}

\author{
Edward W. Holt • Michael S. Verhille
}

Published online: 5 December 2010

(C) Springer Science+Business Media, LLC 2010

Colonoscopy is associated with a reduction in colorectal cancer (CRC) incidence and mortality [1], although this association may be limited to cancers arising in the distal colon [2]. Recently, a prospective randomized controlled trial showed that flexible sigmoidoscopy reduces CRC mortality [3], but a comparable prospective randomized trial for colonoscopy is currently in phase III and will not be completed until 2036 [4]. Nevertheless, the American Cancer Society and the US Preventive Services Task Force recommend screening colonoscopy every 10 years starting at age 50 for patients with average risk of CRC. Likewise, Medicare has covered a majority of the costs of this screening procedure since 2001 for patients at average risk.

The molecular basis for the adenoma-carcinoma sequence in CRC is well described [5]. More recently it was proposed that a genetic pathway characterized by microsatellite instability (MSI) accounts for a number of sporadic CRC [6]. Many of these lesions arise from nonpolypoid lesions in the proximal colon [7]. Although proximal cancers occur less frequently than distal ones, they may more frequently result from a missed precursor lesion at colonoscopy, as an association between interval cancers and both the presence of MSI and proximal location has been reported [8].

This evidence represents a significant challenge to colonoscopists. Distal CRC represents the low-hanging fruit, so to speak, in that its precursor lesions are more numerous, more polypoid and reachable with a shorter, cheaper and safer procedure. Removal of a sufficient number of precursor lesions to significantly reduce mortality from proximal CRC may require a more consistent level of training

E. W. Holt $(\varangle) \cdot$ M. S. Verhille

California Pacific Medical Center, San Francisco, CA, USA

e-mail: edholt@gmail.com and expertise than is currently reported in the literature. In some of the retrospective trials that failed to show a reduction in $\mathrm{CRC}$ mortality from proximal lesions removed at colonoscopy, gastroenterologists comprised a minority of the colonoscopists [2]. In an effort to further lower CRC mortality, many approaches to quality improvement in colonoscopy have been proposed including standards for withdrawal time, withdrawal technique, operator experience, optical enhancement and measurement of adenoma detection rate. However, none of these quality standards will succeed if the colonoscopist cannot consistently visualize an adequate amount of the colonic mucosa. In the end, the quality of the bowel preparation may determine whether screening colonoscopy, rather than flexible sigmoidoscopy, continues to be so universally recommended and reimbursed.

It remains to be seen how to best administer bowel preparation before colonoscopy so that the colonoscopist has greatest opportunity to reduce CRC mortality. We have known for decades that both polyethylene glycol (PEG) and bile take approximately $1 \mathrm{~h}$ to reach the cecum $[9,10]$. It is the goal of a bowel preparation, then, to deliver a sufficient quantity of fluid to the cecum to cleanse the entire colon, allow enough time for the cleansing agent to pass completely through the colon, but not wait so long that the proximal colon is again coated in a film of bilious secretions. With respect to the latter two goals, timing is everything. There have been a number of recent studies, including the present one, which investigated the relationship between timing and quality of bowel preparation [11-18].

In this issue of Digestive Diseases and Sciences, Eun et al. [11] draw an association between the quality of bowel preparation and the interval between the time of last PEG intake and the start of colonoscopy. In this single-center 
prospective study, bowel preparations that were finished within $4 \mathrm{~h}$ of colonoscopy were significantly better than those completed more than $4 \mathrm{~h}$ from the procedure, as measured by the validated Ottawa bowel preparation scale [19]. This interval was considered the same as a $7 \mathrm{~h}$ interval between the start of bowel preparation and the beginning of colonoscopy because a remarkable $84 \%$ of patients consumed the PEG-based prep in the recommended $3 \mathrm{~h}$. The patients were evenly distributed between morning and afternoon colonoscopy start times, but the colonoscopy start time did not independently predict bowel cleanliness. Importantly, there were no differences in bowel preparation completion rates between the two groups. The authors conclude that a shorter end-of-prep to colonoscopy time improves bowel preparation quality. They hypothesize that waiting beyond $4 \mathrm{~h}$ allows accumulation of secreted bile in the right colon, amounting to a "missed opportunity" to evaluate the colon when it is still at its cleanest.

This study reinforces a concept that has been reported in other recent publications (Table 1). It goes farther, however, in more specifically identifying the ideal time interval between bowel preparation and colonoscopy. In a recent flurry of publications, it has been shown repeatedly that a "morning-of" preparation for an afternoon colonoscopy is superior to a "night-before" preparation. The current study, however, suggests that even an interval from end-of-prep to colonoscopy of 7 or $8 \mathrm{~h}$ is inferior to an interval of 3 or $4 \mathrm{~h}$. This suggests that not all "morning-of" preparations are the same, and that bowel preparations may need to be scheduled even more strictly to give colonoscopists the right window of opportunity to find and remove neoplastic lesions. Additionally, these findings challenge recently published data that cecal intubation and adenoma detection rates are lower in the afternoon because of "physician fatigue" [20, 21].

The authors found a difference between the quality of the preparation in the right colon and the remaining parts of the colon in both the morning and afternoon groups (Ottawa scores of 1.5 vs. 0.88 and 0.48 , respectively; no $p$-value reported). This finding supports the hypothesis that the right side of the colon is harder to clean despite the possibility that it is home to some of the hardest polyps to see. The authors of the present study did not report whether the interval from end-of-prep to colonoscopy specifically impacted the Ottawa score in the right colon, only that it significantly impacted the overall score of all the colonic segments combined. Other authors, though, have already made the observation that the right colon can achieve a significantly higher quality preparation when the bowel prep is taken the "morning-of" versus the "night-before" [12-14]. However, data from across different studies cannot be directly compared and a single prospective trial must be performed to determine how many hours post-bowel preparation should elapse until the right colon is primed for detection of even the flattest polyps. At the very least, the right colon can be considered the lowest common denominator for bowel preparations and should be used as a standard by which they are measured.

The present study was well designed and makes a strong association between the timing and quality of bowel preparation, but it does not include data on the penultimate goal: increasing adenoma detection rate. (The ultimate goal, of course, is to lower CRC mortality!) Data examining this specific relationship is sparse. Sanaka et al. [20] demonstrated that adenomas are detected more often in the morning than in the afternoon but did not account for quality of bowel preparation and instead attributed the difference largely to physician fatigue. Harewood et al. [15] linked the quality of bowel preparation to the detection of colonic polyps smaller than $9 \mathrm{~mm}$, but only reported "adequate" versus "inadequate" preparations and did not use a rubric like the Ottawa scale to grade each colonic segment. Parra-Blanco et al. [22] showed that "same-day" bowel preparation was significantly associated with an increased detection of flat lesions, but not protruding lesions, when compared to "night-before" prep. However, the location of these flat lesions and details about bowel preparation quality were not reported. Thus, conclusions on the effect of timing of bowel preparation on adenoma detection rate, specifically in the right colon, can only be drawn from indirect evidence.

Eun and colleagues have contributed to a rapidly expanding body of literature that supports the hypothesis

Table 1 Recent publications comparing timing and quality of bowel preparation

\begin{tabular}{llll}
\hline Author & Year & Optimal prep-to-procedure time & Significance (improved quality) \\
\hline Siddiqui et al. [16] & 2009 & $<14$ h from end of prep (vs. $>14$ h) & $P=0.013$ \\
Eun et al. [11] & 2010 & $<4$ h from end of prep (vs. $>4$ h) & $P<0.02$ \\
Gurudu et al. [17] & 2010 & $3-8$ h from end of prep (vs. 13-18 h) & OR 7.03 (2.57-19.22) \\
Marmo et al. [18] & 2010 & $<8$ h from end of prep (vs. $>8$ h) & $P<0.001$ \\
Varughese et al. [12] & 2010 & $3-7$ h from end of prep (vs. 16-20 h) & $P<0.01$
\end{tabular}

OR odds ratio 
that the interval between bowel preparation and colonoscopy is crucial in determining the quality of the prep and the amount of mucosa visualized. It is generally accepted, though not well documented, that a higher-quality bowel preparation will improve adenoma detection rates throughout the colon. Currently, it can only be inferred that higher adenoma detection rates during colonoscopy will decrease CRC mortality or save lives. Future studies are needed to determine whether maximizing the quality of bowel preparation in the right colon will help us obtain the holy grail of colonoscopy - a decrease in CRC mortality beyond what is already reported with flexible sigmoidoscopy. Should this evidence emerge, it could further change the way both colonoscopists and patients approach this screening procedure, shifting the focus from timing of the procedure to timing of the bowel preparation.

\section{References}

1. Winawer SJ, Zauber AG, Ho MN, et al. Prevention of colorectal cancer by colonoscopic polypectomy. The National Polyp Study Workgroup. N Engl J Med. 1993;329:1977-1981.

2. Baxter NN, Goldwasser MA, Paszat LF, et al. Association of colonoscopy and death from colorectal cancer. Ann Intern Med. 2009;150:1-8.

3. Atkin WS, Edwards R, Kralj-Hans I, et al. Once-only flexible sigmoidoscopy screening in prevention of colorectal cancer: a multicentre randomised controlled trial. Lancet. 2010;375: 1624-1633.

4. Clinical trials.gov. The Northern-European initiative on colorectal cancer (NordICC). Available at: http://www.clinicaltrials. gov/ct2/show/NCT00883792. Accessed 10 November 2010.

5. Vogelstein B, Fearon ER, Hamilton SR, et al. Genetic alterations during colorectal-tumor development. N Engl J Med. 1988;319: 525-532.

6. Hawkins NJ, Ward RL. Sporadic colorectal cancers with microsatellite instability and their possible origin in hyperplastic polyps and serrated adenomas. J Natl Cancer Inst. 2001;93:1307-1313.

7. Konishi K, Takimoto M, Kaneko K, et al. BRAF mutations and phosphorylation status of mitogen-activated protein kinases in the development of flat and depressed-type colorectal neoplasias. $\mathrm{Br}$ J Cancer. 2006;94:311-317.

8. Shaukat A, Arain M, Thaygarajan B, et al. Is BRAF mutation associated with interval colorectal cancers? Dig Dis Sci. 2010; $55: 2352-2356$.
9. Bond JH, Levitt MD, Prentiss R, et al. Investigation of small bowel transit time in man utilizing pulmonary hydrogen $(\mathrm{H} 2)$ measurements. J Lab Clin Med. 1975;85:546-555.

10. Marcus SN, Heaton KW. Intestinal transit, deoxycholic acid and the cholesterol saturation of bile-three inter-related factors. Gut. 1986;27:550-558.

11. Eun CS, Han DS, Hyun YS, et al. The timing of bowel preparation is more important than the timing of colonoscopy in determining the quality of bowel cleansing. Dig Dis Sci. doi: 10.1007/s10620-010-1457-1

12. Varughese S, Kumar AR, George A, et al. Morning-only onegallon polyethylene glycol improves bowel cleansing for afternoon colonoscopies: a randomized endoscopist-blinded prospective study. Am J Gastroenterol. 2010;105:2368-2374.

13. Gupta T, Mandot A, Desai D, et al. Comparison of two schedules (previous evening versus same morning) of bowel preparation for colonoscopy. Endoscopy. 2007;39:706-709.

14. Church JM. Effectiveness of polyethylene glycol antegrade gut lavage bowel preparation for colonoscopy-timing is the key! Dis Colon Rectum. 1998;41:1223-1225.

15. Harewood GC, Sharma VK, de Garmo P. Impact of colonoscopy preparation quality on detection of suspected colonic neoplasia. Gastrointest Endosc. 2003;58:76-79.

16. Siddiqui AA, Yang K, Spechleret SJ, et al. Duration of the interval between the completion of bowel preparation and the start of colonoscopy predicts bowel-preparation quality. Gastrointest Endosc. 2009;69:700-706.

17. Gurudu SR, Ratuapli S, Heigh R, et al. Quality of bowel cleansing for afternoon colonoscopy is influenced by time of administration. Am J Gastroenterol. 2010;105:2318-2322.

18. Marmo R, Rotondano G, Riccio G, et al. Effective bowel cleansing before colonoscopy: a randomized study of split-dosage versus non-split dosage regimens of high-volume versus lowvolume polyethylene glycol solutions. Gastrointest Endosc. 2010;72:313-320.

19. Rostom A, Jolicoeur E. Validation of a new scale for the assessment of bowel preparation quality. Gastrointest Endosc. 2004;59:482-486.

20. Sanaka MR, Shah N, Mullen KD, et al. Afternoon colonoscopies have higher failure rates than morning colonoscopies. Am J Gastroenterol. 2006;101:2726-2730.

21. Sanaka MR, Deepinder F, Thota PN, et al. Adenomas are detected more often in morning than in afternoon colonoscopy. Am J Gastroenterol. 2009;104:1659-1664.

22. Parra-Blanco A, Nicolas-Perez D, Gimeno-Garcia A, et al. The timing of bowel preparation before colonoscopy determines the quality of cleansing, and is a significant factor contributing to the detection of flat lesions: a randomized study. World J Gastroenterol. 2006;12:6161-6166. 